\title{
Allergic diseases and asthma in the family predict the persistence and onset-age of asthma: a prospective cohort study
}

Elina MS Paaso ${ }^{1,2}$, Maritta S Jaakkola1,2,3,5, Aino K Rantala ${ }^{1,4}$, Timo T Hugg ${ }^{1,4,5}$ and Jouni JK Jaakkola ${ }^{1,2,4,5^{*}}$

\begin{abstract}
Background: Family history of asthma and other allergic diseases have been linked to the risk of childhood asthma previously, but little is known about their effect on the age-of-onset and persistency of asthma until young adulthood.

Methods: We assessed the effect of the family history of asthma and allergic diseases on persistent vs. transient, and early- vs. late-onset persistent asthma in The Espoo Cohort Study 1991-2011, a population-based cohort study of 1623 subjects (follow-up rate 63.2\%). The determinants were any family history (any parent or sibling); maternal; paternal; siblings only; parents only; and both siblings and parents. Analyses were conducted separately for asthma and allergic diseases while taking the other disease into account as a confounding factor. The outcomes were persistent, transient, early-onset persistent ( $<13$ years) and late-onset persistent asthma. Adjusted risk ratios (RR) were calculated applying Poisson regression. Q-statistics were used to assess heterogeneity between RRs.

Results: Family history was associated with the different subtypes but the magnitude of effect varied quantitatively. Any family history of asthma was a stronger determinant of persistent (adjusted $\mathrm{RR}=2.82,95 \% \mathrm{Cl} 1.99-4.00$ ) than transient asthma $(1.65,1.03-2.65)$ (heterogeneity: $P=0.07)$ and on early-onset than late-onset persistent asthma. Also any family history of allergic diseases was a stronger determinant of persistent and early-onset asthma. The impact of paternal asthma continued to young adulthood (early-onset: 3.33, 1.57-7.06 vs. late-onset 2.04, 0.75-5.52) while the influence of maternal asthma decreased with age (Early-onset 3.94, 2.11-7.36 vs. Late-onset 0.88, 0.28-2.81). Paternal allergic diseases did not follow the pattern of paternal asthma, since they showed no association with late-onset asthma. Also the effect estimates for other subtypes were lower than in other hereditary groups (persistent 1.29, $0.75-2.22$ vs. transient $1.20,0.67-2.15$ and early-onset $1.86,0.95-3.64$ vs. late-onset $0.64,0.22-1.80$ ).
\end{abstract}

Conclusions: Family history of asthma and allergic diseases are strong determinants of asthma, but the magnitude of effect varies according to the hereditary group so that some subtypes have a stronger hereditary component, and others may be more strongly related to environmental exposures. Our results provide useful information for assessing the prognosis of asthma based on a thorough family history.

Keywords: Asthma, Allergic diseases, Family history, Heredity, Cohort study, Risk ratio, Longitudinal study, Heterogeneity, Epidemiology, Age of onset

\footnotetext{
* Correspondence: jouni.jaakkola@oulu.fi

${ }^{1}$ Center for Environmental and Respiratory Health Research, University of

Oulu, PO Box 5000, Fl-90014 Oulu, Finland

${ }^{2}$ Respiratory Medicine Unit, Department of Medicine, Oulu University

Hospital, Oulu, Finland

Full list of author information is available at the end of the article
}

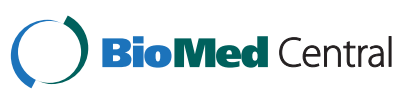

(c) 2014 Paaso et al.; licensee BioMed Central Ltd. This is an Open Access article distributed under the terms of the Creative Commons Attribution License (http://creativecommons.org/licenses/by/4.0), which permits unrestricted use, distribution, and reproduction in any medium, provided the original work is properly credited. The Creative Commons Public Domain Dedication waiver (http://creativecommons.org/publicdomain/zero/1.0/) applies to the data made available in this article, unless otherwise stated. 


\section{Background}

Family history of asthma and allergic diseases have been linked to the risk of childhood asthma [1-3]. In our recent article we showed that family history of asthma is a strong determinant of developing asthma through childhood and into young adulthood [4], and the role of heredity has also been shown to influence adult-onset asthma [5].

Even though asthma is considered a chronic condition, especially children may recover from it [6]. Asthma manifests clinically as different subtypes of disease, including persistent and transient and early and late onset asthma, which may be related to different hereditary patterns $[7,8]$. Our systematic search identified only two previous longitudinal studies assessing the impact of heredity on the development of different subtypes of asthma, both expanding from birth to 6 years of age $[2,8]$. These two studies focused on maternal asthma only, and the influence of paternal asthma, siblings' asthma and the effect of hereditary allergic diseases has only been addressed in cross-sectional studies [1,3,9]. Also, since all of these studies were conducted among children, they focused mostly on childhood wheezing patterns and only few studies applied doctor-diagnosed asthma $[1,3]$.

Hereditary patterns are complex and assessment of their impact requires longitudinal studies expanding from early childhood to adulthood. Also, previous studies on this topic were mostly conducted on small children and therefore assessing the effects on doctor-diagnosed asthma instead of wheezing patterns is difficult. To capture the dynamics of developing asthma and potentially recovering from it in relation to parental and siblings' asthma and allergic disease, we utilized The Espoo Cohort Study, a population-based 20-year prospective follow-up.

\section{Methods \\ Study population}

The source population included all children of the city of Espoo who were born between January, 1984 and March, 1990. A parent-administered baseline questionnaire was distributed in March 1991 to a random sample of children drawn from the roster of Statistics Finland [10]. The baseline population included 2568 children whose parents filled in the questionnaire and in March 1997, a six-year follow-up survey of the cohort was conducted with a follow-up rate of $77.3 \%$. Details of the baseline study population and six-year cohort have been described elsewhere [10,11]. In 201011 we conducted the 20-year follow-up with 1623 participants (63.2\% of the baseline). The present analyses focused on this 20-year cohort. The study protocol was approved by the Ethics Committee of the Oulu University Hospital District.

\section{Health outcome}

The outcome of interest was the development of asthma from the birth to the end of the study period. In the baseline and the 6-year follow-up the outcome information was based on the question answered by a parent/guardian: "Has the child ever had doctor diagnosed asthma? If yes, at what age did it start?" In the 20-year follow up the study subjects themselves answered the corresponding question.

We defined two categories of asthma according to its dynamics: persistent and transient. Persistent asthma was defined as the presence of asthma with asthmatic symptoms (cough, phlegm production, wheezing, and shortness of breath when not having flu) and/or medication use in all the follow-ups after the first indication of doctor-diagnosed asthma. If asthma was diagnosed between the 6-year and 20-year follow-ups a minimum duration of 5 years was required to categorize the disease as persistent $(n=52)$. Transient asthma was defined as the presence of asthma at baseline or the 6-year follow-up and lack of asthmatic symptoms and asthma medication in the 20-year followup. We excluded 11 subjects with asthma who had experienced a relapse, because they did not represent either the transient or the persistent subgroup of asthmatics thus forming an interesting subtype to be studied further. We also excluded 8 subjects who had had asthma for less than 5 years. Thus, the total population in the present analyses included 1604 subjects. We defined early- and late-onset asthma using a cut-off point of 13 years. There were 40 people with missing information on the onset-age of asthma in the baseline-population of 2568. This information was complemented as described elsewhere [4].

\section{Definition of asthma and allergic diseases in first-degree relatives}

The presence of parental asthma was defined using information from all the three questionnaires. The information on siblings' asthma status was only asked in the 6- and 20year follow-ups. We excluded 4 subjects from the sibling asthma analyses due to missing information. The information on parental allergic diseases was required in all three follow-ups whereas siblings' allergic disease status was only asked in the 20-year follow-up questionnaire. In the baseline and 6-year follow-ups the parental allergic disease status concerned only allergic rhinitis, whereas in the 20year follow-up the question included allergic rhinitis, allergic conjunctivitis and allergic (atopic) dermatitis without further elaborating which of the different condition(s) were present. 22 subjects were excluded from the siblings' and 3 from the parental allergic disease analyses due to missing information.

\section{Covariates}

Several potential determinants of asthma were included in the analyses to get the best unbiased estimates of the 
relation between heredity and the risk of asthma. The information on the covariates was collected from all the three questionnaires. The following variables were adjusted for in the analyses: age [12], sex [13], family socioeconomic status at baseline [14], duration of breast-feeding [15], second-hand smoke exposure at the age of 0 to 3 years [16], mold exposure during the first three years of life [11] and maternal smoking in pregnancy [16]. In the analyses of late-onset persistent asthma the mold and second-hand smoke exposures were taken into account up to the age of 13. The coexistence of hereditary asthma and allergic diseases was taken into account by adjusting for the other disease in the analyses.

\section{Statistical methods}

First, we compared the occurrence of persistent and transient asthma, and early-onset and late-onset persistent asthma according to the following hereditary categories: 1) any heredity (either one or both parents and/ or any siblings); 2) maternal (only mother); 3) paternal (only father); 4) both parents (both parents) 5) siblings only (only siblings, not parents); 6) parents only (only parents, not siblings); 7) both groups (both siblings and parents) 8) using no family history as the reference category. The same categories were formed separately for asthma and allergic diseases.

Second, we quantified the relations between heredity and type of asthma using Poisson regression analysis using the proc genmod -procedure in SAS statistical software package (SAS, version 9.3, SAS Institute, Cary, NC). The resulting RRs were adjusted for potential confounding. Finally, we assessed the difference between adjusted RRs for persistent vs. transient asthma and early- vs. late-onset asthma using Q-statistics for heterogeneity. Heterogeneity Q-statistics were calculated with the derSimonian-Laird method with a SAS-macro provided by Herzmark and Spiegelman $[17,18]$. The greater the Q-statistics and the smaller the P-value, the greater the heterogeneity between the studied RRs. The 95\% confidence intervals (95\% CI) for the incidence rates in Figure 1 were calculated with a SAS macro by Daly [19].

\section{Results}

\section{Characteristics of the study population}

Table 1 presents the characteristics of the baseline, 6year and 20-year study population. The 20-year cohort used in these analyses did not differ substantially from the baseline study population indicating that selection bias is not an issue in this cohort.

The occurrence of persistent, early- and late-onset persistent and transient asthma and the percentage of subjects without any asthma according to the different categories of hereditary asthma and allergic diseases are shown in Table 2. The overall incidence rates of asthma

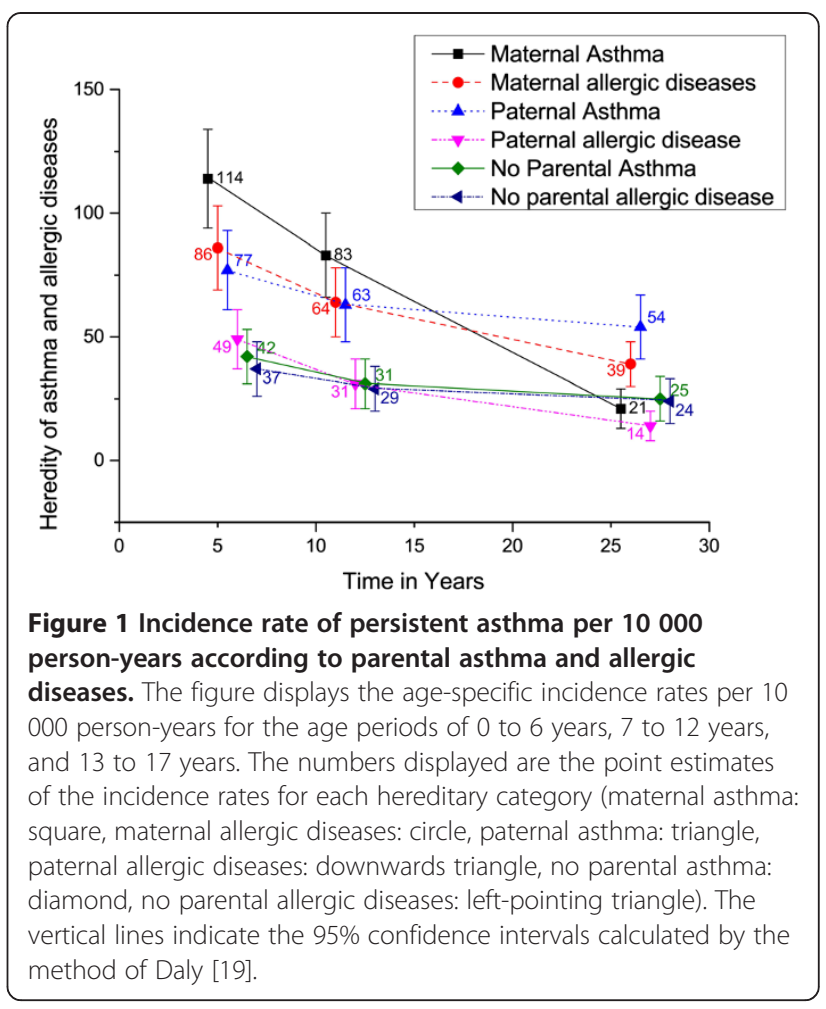

per 10000 person-years were 70.7 (95\% CI 55.2-89.2) for asthma in general, 39.9 (28.5-54.3) for persistent asthma, 25.6 (16.7-37.6) for transient asthma, 26.2 (17.138.3) for early-onset asthma and 13.7 (7.4-23.1) for lateonset asthma.

\section{Transient versus persistent asthma}

Table 3 shows that heredity has a stronger impact on the risk of persistent asthma compared to transient asthma. In the group of any family history of asthma, the adjusted RR for persistent asthma was 2.82, 95\% CI 1.99-4.00, whereas the $\mathrm{RR}$ of developing transient asthma was 1.65 , 95\% CI 1.03-2.65. The Q-statistics indicated heterogeneity between the effect estimates $(\mathrm{Q}=3.20, P=0.07)$. For any family history of allergic diseases the adjusted RR for persistent asthma was 2.20 , with $95 \%$ CI $1.48-3.28$ and for transient asthma was $1.02(0.66-1.58)(\mathrm{Q}=6.50, P=0.01)$. The other hereditary groups showed smaller effect estimates for developing transient asthma in comparison to higher estimates for developing persistent asthma (Table 3). An exception to this was seen with paternal allergic diseases where both the $\mathrm{RR}$ for developing persistent asthma as well as the RR for transient asthma were virtually equal and non-significant (Persistent asthma: 1.29, 0.75-2.22; Transient asthma: 1.20, 0.67-2.15; heterogeneity $\mathrm{Q}=0.03, P=0.86$ ).

\section{Early- versus late-onset persistent asthma}

Heredity plays the most important role as the determinant of the early-onset persistent asthma, using 13 years 
Table 1 Personal and environmental characteristics of the baseline study population, those lost to follow-up, the 6-year cohort and the 20-year cohort, the espoo cohort study 1991-2011, Finland

\begin{tabular}{|c|c|c|c|c|c|c|}
\hline & Baseline & $\begin{array}{l}\text { Lost to } \\
\text { follow-up }\end{array}$ & 6-year cohort & $\begin{array}{l}\text { Lost to } \\
\text { follow-up }\end{array}$ & 20-year cohort & Participation in all surveys \\
\hline No. (\% of baseline population) & $2568(100.0)$ & $584(22.7)$ & $1984(77.3)$ & $945(36.8)$ & $1623(63.2)$ & $1298(50.5)$ \\
\hline \multicolumn{7}{|l|}{ Age (years) } \\
\hline 1 & $424(16.5)$ & $100(17.1)$ & $324(16.3)$ & $156(16.5)$ & $268(16.5)$ & $210(16.2)$ \\
\hline 2 & $405(15.8)$ & $104(17.8)$ & $301(15.2)$ & $147(15.6)$ & $258(15.9)$ & 199 (15.3) \\
\hline 3 & $411(16.0)$ & $92(15.8)$ & $319(16.1)$ & $145(15.3)$ & $266(16.4)$ & $211(16.3)$ \\
\hline 4 & $400(15.6)$ & $67(11.5)$ & $333(16.8)$ & $159(16.8)$ & $241(14.9)$ & $209(16.1)$ \\
\hline 5 & $415(16.2)$ & $101(17.3)$ & $314(15.8)$ & $151(16.0)$ & $264(16.3)$ & $208(16.0)$ \\
\hline $6-7$ & $513(20.0)$ & $120(20.6)$ & $393(19.8)$ & $187(19.8)$ & $326(20.1)$ & $261(20.1)$ \\
\hline \multicolumn{7}{|l|}{ Sex } \\
\hline male & $1311(51.1)$ & $309(52.9)$ & $1002(50.5)$ & $557(58.9)$ & $754(46.5)$ & $592(45.6)$ \\
\hline female & $1257(49.0)$ & $275(47.1)$ & $982(49.5)$ & $388(41.1)$ & $869(53.5)$ & $706(54.4)$ \\
\hline \multicolumn{7}{|c|}{ Family socioeconomic status at baseline } \\
\hline low & $667(26.1)$ & $169(29.1)$ & $498(25.2)$ & $296(31.5)$ & $371(22.9)$ & $292(22.5)$ \\
\hline middle/high & $1889(73.9)$ & $411(70.9)$ & $1478(74.8)$ & $643(68.5)$ & $1246(77.1)$ & $1003(77.5)$ \\
\hline \multicolumn{7}{|c|}{ Duration of breast-feeding in months } \\
\hline$<4$ & $481(19.3)$ & $135(24.1)$ & $346(17.9)$ & $192(21.0)$ & $289(18.3)$ & $221(17.5)$ \\
\hline $4 \leq x<8$ & $670(26.9)$ & $159(28.3)$ & $511(26.4)$ & $250(27.4)$ & $420(26.6)$ & $333(26.3)$ \\
\hline$\geq 8$ & $1343(53.9)$ & $267(47.6)$ & $1076(55.7)$ & $471(51.6)$ & $872(55.2)$ & $711(56.2)$ \\
\hline \multicolumn{7}{|l|}{$\mathrm{SHS}_{0-3}$} \\
\hline yes & $299(11.6)$ & $66(11.3)$ & $233(11.7)$ & $105(11.1)$ & $194(12.0)$ & $153(11.8)$ \\
\hline no & $2269(88.4)$ & $518(88.7)$ & $1751(88.3)$ & $840(88.9)$ & $1429(88.1)$ & $1145(88.2)$ \\
\hline \multicolumn{7}{|l|}{ Mold $_{0-3}$} \\
\hline yes & $138(5.4)$ & $21(3.6)$ & $117(5.9)$ & $55(5.8)$ & $83(5.1)$ & $73(5.6)$ \\
\hline no & $2428(94.6)$ & $569(96.4)$ & $1867(94.1)$ & $888(94.2)$ & $1540(94.9)$ & $1225(94.4)$ \\
\hline \multicolumn{7}{|l|}{$\mathrm{SHS}_{0-13}^{*}$} \\
\hline yes & $468(18.2)$ & $121(20.7)$ & $347(17.5)$ & $161(17.0)$ & $307(18.9)$ & $234(18.0)$ \\
\hline no & $2100(81.8)$ & $463(79.3)$ & $1637(82.5)$ & $784(83.0)$ & $1316(81.1)$ & $1064(82.0)$ \\
\hline \multicolumn{7}{|l|}{ Mold $_{0-13}^{*}$} \\
\hline yes & $385(15.0)$ & $35(6.0)$ & $350(17.6)$ & $150(15.9)$ & $235(14.5)$ & $220(17.0)$ \\
\hline no & $2183(85.0)$ & $549(94.0)$ & $1634(82.4)$ & $795(84.1)$ & $1388(85.5)$ & $1078(83.1)$ \\
\hline \multicolumn{7}{|l|}{ Maternal smoking in pregnancy } \\
\hline yes & $364(14.2)$ & $104(17.9)$ & $260(13.1)$ & $160(17.0)$ & $204(12.6)$ & $156(12.0)$ \\
\hline no & 2199 (85.8) & $477(82.1)$ & $1722(86.9)$ & 784 (83.1) & 1415 (87.4) & $1141(88.0)$ \\
\hline
\end{tabular}

Abbreviations: $\mathrm{SHS}_{0-3}=$ exposure to second-hand smoke at the age of 0-3, $\mathrm{SHS}_{0-13}=$ exposure to second-hand smoke at the age of 0-13.

Missing information: 12 for family socioeconomic status at baseline, 74 for duration of breast-feeding, 5 for maternal smoking in pregnancy, 2 from mold-exposure from 0 to 3 years.

*Used for adjustment when studying late-onset asthma as the outcome.

of age as the cut-off point (Table 4). Almost all the effects of the hereditary determinants showed substantial heterogeneity between early- and late-onset asthma. The strongest risk for developing early-onset asthma was detected in the hereditary group both parents with asthma where the adjusted RR was 9.61 (95\% CI 3.93-23.45), and both parents and siblings having asthma. With family history of allergic diseases these were the same groups with highest RRs. (Table 4) Interestingly, increased risk related to paternal asthma extended to late-onset persistent asthma (adjusted RR 2.04, 95\% CI 0.75-5.52), but the effect related to maternal asthma diminished with age (adjusted RR 0.88, 95\% CI 0.28-2.81). This pattern was not replicated with paternal allergic disease, which showed some effect on 
Table 2 The prevalences of different subtypes of asthma according to hereditary groups, the espoo cohort study 1991-2011, Finland

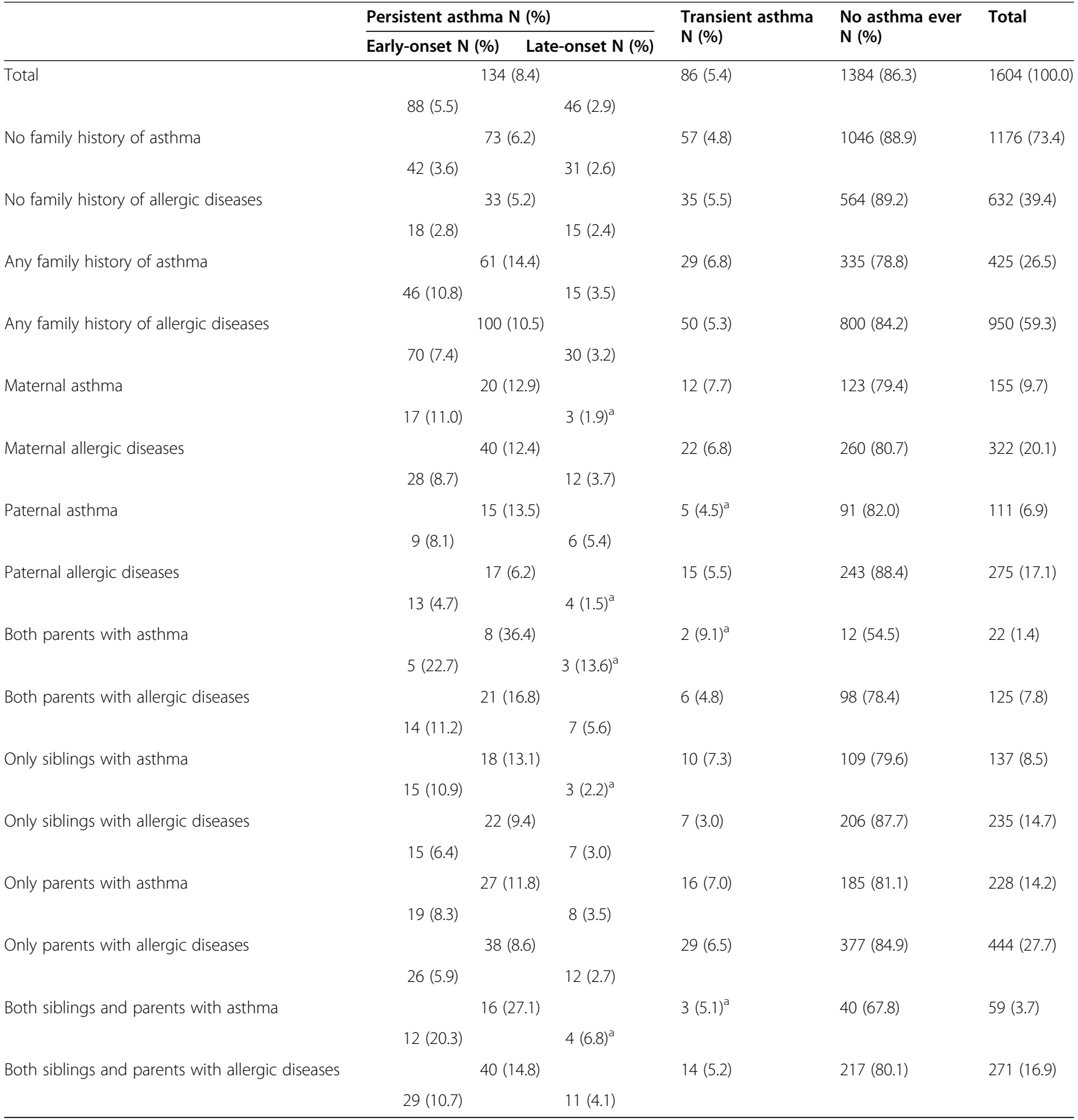

$\%$ is the percentage of people that represent the corresponding subtype of asthma divided by the total number of people that have the risk factor mentioned in that line (e.g. maternal asthma, paternal allergic diseases, total $\mathrm{n}$ in the group mentioned in the last column of the table).

${ }^{a}$ Restricted amount of observations in the cell may lead to chance variation in the results.

19 people excluded from the analyses due to either asthma relapse $(\mathrm{N}=11)$ or follow-up time of less than 5 years $(\mathrm{N}=8)$.

Missing information: 1 in parental asthma, 4 for siblings with asthma, 3 in parental allergic diseases, 22 in siblings with allergic diseases.

early-onset persistent asthma (adjusted RR 1.86, 95\% CI = 0.95-3.64) but null effect on late-onset persistent asthma (adjusted RR 0.64, 95\% CI 0.22-1.80). To highlight the difference between maternal and paternal asthma and allergic diseases on the development of childhood asthma we also calculated age-specific incidence rates from 0-6 years of age, 6-12 years of age and 13-27 years of age. (Figure 1). The incidence rate of persistent asthma related to no parental asthma decreases only slightly over time while the incidence rate of persistent asthma related to maternal 
Table 3 The influence of family history of asthma on persistent and transient asthma, The Espoo Cohort Study 1991-2011, Finland

\begin{tabular}{|c|c|c|c|c|c|}
\hline \multirow{3}{*}{ Family history of asthma } & \multicolumn{2}{|c|}{ Persistent asthma vs. no asthma } & \multicolumn{2}{|c|}{ Transient asthma vs. no asthma } & \multirow{3}{*}{$\begin{array}{l}\text { Heterogeneity } \\
\text { Q-statistic, } \\
\text { P-value }\end{array}$} \\
\hline & $\mathbf{R R}$ & $\mathbf{R R}^{\mathrm{a}}$ & RR & $\mathrm{RR}^{\mathrm{a}}$ & \\
\hline & $(95 \% \mathrm{Cl})$ & $(95 \% \mathrm{Cl})$ & $(95 \% \mathrm{Cl})$ & $(95 \% \mathrm{Cl})$ & \\
\hline Parents or siblings with asthma & $2.62(1.88-3.65)$ & $2.82(1.99-4.00)$ & $1.56(0.99-2.43)$ & $1.65(1.03-2.65)$ & $3.20,0.07$ \\
\hline Parents or siblings with allergic diseases & $2.11(1.45-3.09)$ & $2.20(1.48-3.28)$ & $0.98(0.65-1.49)$ & $1.02(0.66-1.58)$ & $6.50,0.01$ \\
\hline Maternal asthma & $2.42(1.47-3.98)$ & $2.50(1.50-4.15)$ & $1.64(0.89-3.04)$ & $1.57(0.79-3.11)$ & $1.35,0.25$ \\
\hline Maternal allergic disease & $2.31(1.54-3.46)$ & $2.17(1.40-3.37)$ & $1.44(0.88-2.38)$ & $1.48(0.87-2.52)$ & $1.18,0.77$ \\
\hline Paternal asthma & $2.47(1.43-4.28)$ & $2.70(1.52-4.80)$ & $0.97(0.39-2.40)$ & $1.10(0.44-2.73)$ & $0.85,0.35$ \\
\hline Paternal allergic disease & $1.13(0.66-1.94)$ & $1.29(0.75-2.22)$ & $1.07(0.61-1.91)$ & $1.20(0.67-2.15)$ & $0.03,0.86$ \\
\hline Both parents with asthma & $6.92(3.76-12.71)$ & $6.70(3.34-13.45)$ & $2.64(0.71-9.86)$ & $2.94(0.80-10.87)$ & $4.24,0.04$ \\
\hline Both parents with allergic disease & $3.05(1.88-4.95)$ & $3.32(2.01-5.47)$ & $1.07(0.46-2.45)$ & $0.97(0.39-2.40)$ & $5.41,0.02$ \\
\hline Siblings with asthma only & $2.11(1.31-3.40)$ & $2.33(1.42-3.84)$ & $1.62(0.85-3.09)$ & $1.79(0.93-3.45)$ & $7.36,0.01$ \\
\hline Siblings with allergic disease only & $1.67(0.99-2.80)$ & $1.75(1.02-3.01)$ & $0.57(0.26-1.27)$ & $0.63(0.28-1.41)$ & $4.27,0.04$ \\
\hline Parents with asthma only & $2.41(1.52-3.84)$ & $2.50(1.54-4.06)$ & $1.55(0.88-2.73)$ & $1.56(0.85-2.87)$ & $4.29,0.04$ \\
\hline Parents with allergic disease only & $1.84(1.16-2.92)$ & $1.82(1.12-2.97)$ & $1.19(0.74-1.91)$ & $1.23(0.75-2.03)$ & $1.20,0.27$ \\
\hline Parents and siblings with asthma & $5.52(3.31-9.20)$ & $5.97(3.48-10.22)$ & $1.39(0.45-4.32)$ & $1.64(0.52-5.14)$ & $17.40,0.00$ \\
\hline Parents and siblings with allergic disease & $3.13(2.00-4.90)$ & $3.48(2.18-5.56)$ & $1.01(0.55-1.84)$ & $1.02(0.54-1.92)$ & $9.40,0.00$ \\
\hline
\end{tabular}

19 People excluded from the analyses due to follow-up period of less than 5 years $(n=8)$ or asthma relapse $(n=11)$.

${ }^{a}$ Adjusted for sex, age, family socioeconomic status at baseline, maternal smoking in pregnancy, SHS at the age of 0-3, mold exposure at the age of 0-3, and duration of breast-feeding.

${ }^{\mathrm{b}}$ Heterogeneity calculated between the adjusted risk ratios of persistent and transient asthma.

Table 4 The influence of family history of asthma and allergic diseases on early- and late-onset persistent asthma, The Espoo Cohort Study 1991-2011, Finland

\begin{tabular}{|c|c|c|c|c|c|}
\hline \multirow[b]{2}{*}{ Family history of asthma } & \multicolumn{2}{|c|}{$\begin{array}{l}\text { Early onset persistent } \\
\text { asthma vs. no asthma }\end{array}$} & \multicolumn{2}{|c|}{$\begin{array}{l}\text { Late onset persistent } \\
\text { asthma vs. no asthma }\end{array}$} & \multirow{2}{*}{$\begin{array}{l}\text { Heterogeneity } \\
\text { (Q-statistic, } \\
\text { P-value) }\end{array}$} \\
\hline & $\begin{array}{l}\mathrm{RR} \\
(95 \% \mathrm{Cl})\end{array}$ & $\begin{array}{l}\mathrm{RR}^{\mathrm{a}} \\
(95 \% \mathrm{Cl})\end{array}$ & $\begin{array}{l}\mathrm{RR} \\
(95 \% \mathrm{Cl})\end{array}$ & $\begin{array}{l}\mathrm{RR}^{\mathbf{b}} \\
(95 \% \mathrm{Cl})\end{array}$ & \\
\hline Parents or siblings with asthma & $3.58(2.37-5.41)$ & $4.10(2.66-6.32)$ & $1.57(0.84-2.92)$ & $1.44(0.73-2.84)$ & $6.47,0.01$ \\
\hline Parents or siblings with allergic diseases & $2.79(1.70-4.60)$ & $3.24(1.89-5.58)$ & $1.43(0.77-2.67)$ & $1.26(0.67-2.38)$ & $4.94,0.03$ \\
\hline Maternal asthma & $3.60(2.00-6.50)$ & $3.94(2.11-7.36)$ & $0.92(0.28-3.07)$ & $0.88(0.28-2.81)$ & $4.98,0.03$ \\
\hline Maternal allergic disease & $2.89(1.71-4.86)$ & $3.04(1.72-5.35)$ & $1.71(0.84-3.47)$ & $1.27(0.58-2.80)$ & $3.07,0.08$ \\
\hline Paternal asthma & $2.70(1.30-5.61)$ & $3.33(1.57-7.06)$ & $2.42(0.99-5.91)$ & $2.04(0.75-5.52)$ & $0.60,0.44$ \\
\hline Paternal allergic disease & $1.51(0.78-2.90)$ & $1.86(0.95-3.64)$ & $0.63(0.22-1.83)$ & $0.64(0.22-1.80)$ & $2.89,0.09$ \\
\hline Both parents with asthma & $8.73(3.80-20.04)$ & $9.61(3.93-23.45)$ & $7.75(2.57-23.39)$ & $5.46(1.30-22.98)$ & $0.42,0.51$ \\
\hline Both parents with allergic disease & $3.71(1.99-6.92)$ & $4.48(2.35-8.57)$ & $2.58(1.11-5.99)$ & $2.41(0.98-5.94)$ & $1.20,0.27$ \\
\hline Siblings with asthma only & $2.96(1.70-5.15)$ & $3.30(1.84-5.92)$ & $0.95(0.30-3.04)$ & $1.10(0.33-3.61)$ & $4.44,0.04$ \\
\hline Siblings with allergic disease only & $2.08(1.06-4.08)$ & $2.31(1.11-4.78)$ & $1.24(0.52-2.96)$ & $1.24(0.52-2.99)$ & $1.13,0.29$ \\
\hline Parents with asthma only & $3.24(1.79-5.86)$ & $3.89(2.10-7.20)$ & $1.60(0.70-3.62)$ & $1.21(0.49-2.96)$ & $2.64,0.10$ \\
\hline Parents with allergic disease only & $2.43(1.34-4.41)$ & $2.85(1.51-5.39)$ & $1.25(0.58-2.71)$ & $0.92(0.40-2.13)$ & $4.41,0.04$ \\
\hline Parents and siblings with asthma & $8.19(4.31-15.57)$ & $9.24(4.68-18.22)$ & $3.58(1.27-10.14)$ & $3.38(1.13-10.18)$ & $2.31,0.13$ \\
\hline Parents and siblings with allergic disease & $4.44(2.49-7.92)$ & $5.50(2.95-10.24)$ & $1.96(0.89-4.29)$ & $1.93(0.87-4.30)$ & $3.36,0.02$ \\
\hline
\end{tabular}

19 People excluded from the analyses due to follow-up period of less than 5 years $(n=8)$ or asthma relapse $(n=11)$.

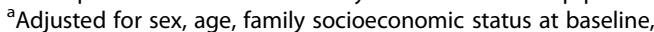

maternal smoking in pregnancy, SHS at the age of $0-3$, mold exposure at the age of $0-3$, and duration of breast-feeding.

${ }^{\mathrm{b}}$ Adjusted for sex, age, family socioeconomic status at baseline,

maternal smoking in pregnancy, SHS from birth to 13 years of age, duration of breast-feeding, mold exposure from birth to the age of 13 .

${ }^{\mathrm{c}}$ Heterogeneity calculated between the adjusted risk ratios of early-onset and late-onset persistent asthma. 
asthma decreases significantly over time. Also the incidence rates of maternal and paternal allergic diseases decrease with time while the effect of paternal asthma on the incidence rate of persistent asthma remains nearly constant through the age periods.

\section{Discussion \\ Main findings}

This population-based prospective 20-year cohort study provides evidence that hereditary asthma and allergic diseases are consistently determinants of different subtypes of asthma, especially persistent rather than transient and early-onset rather than late-onset persistent asthma. The effect related to paternal asthma seemed to remain more constant over time as that of maternal asthma as shown in Figure 1. Both of these findings are consistent with the results of a Finnish population-based case-control study of adult-onset asthma, where paternal asthma was shown to have a stronger effect of adult onset asthma compared with maternal asthma [5]. Interestingly, paternal allergic diseases didn't seem to follow this pattern and showed small, non-significant effects on all of the subtypes studied with early-onset persistent asthma being the only subtype with an elevated risk ratio. (Figure 1; Tables 3 and 4).

\section{Validity of results}

According to our systematic literature search, the current study has the longest follow-up of the studies concerning heredity and development and dynamics of asthma. This enabled us to assess the role of hereditary asthma in both early- versus late-onset as well as persistent versus transient asthma up to adulthood. As shown in Table 1, the baseline - and the 20-year follow-up populations were similar, which assures that selection bias is not an issue in this study.

The definition of asthma was based on parent- or selfreported doctor-diagnosed asthma. Due to the national health care system the access to medical care has excellent coverage in Finland, and the special reimbursement provided nationally for asthma medications provides an economic incentive for actually having potential asthma diagnosed by a physician. These factors are likely to reduce misclassification of asthma in our study population. In addition, according to the study of Pattaro et al. utilizing the age of asthma onset in the analyses improves the validity of the estimate of the incidence of asthma [20]. Most of the previous studies on this subject focus on childhood wheezing patterns, since the diagnosis of asthma is difficult among children [2,7-9]. In our study, the participants have been followed for 20 years and thus making verification of their asthma diagnosis easier especially for more persistent type of asthma. Also, the classification of persistent asthma required both a positive answer to the question on asthma diagnosis as well as symptoms or medication use, making the diagnosis even stronger.

Having information on the age of onset enabled us to categorize the asthma subtype into early- and late-onset asthma. We used the cut-off point of 13 years for this, which is consistent with a previous study suggesting that asthma starting earlier than 12 years forms a different phenotype [21]. The categorization into transient and persistent asthma was based on the diagnosis of asthma in combination with information on asthma symptoms and/or medication use, which were also collected with the questionnaire.

As sensitivity analyses, we also used eight years as the cut-off point, which resulted in the following crude effect estimates: early-onset: maternal asthma 2.87, 95\% CI 1.54-5.36, and paternal asthma 1.72, 95\% CI 0.634.68; late-onset: maternal asthma 1.47, 95\% CI 0.713.03, and paternal asthma 2.42, 95\% CI 1.19-4.89. The same risk ratios for maternal allergic disease was for early-onset asthma 3.36, 95\% CI 1.64-6.87 and for lateonset asthma 2.59, 95\% CI 1.37-4.91 and for paternal allergic disease early-onset asthma adjusted $\mathrm{RR}=2.16$, 95\% CI 0.97-4.78 and late-onset 0.95, 95\% CI 0.37-2.47. This strengthens the evidence that the influence of paternal asthma continues also after childhood as seen in our analyses in Table 4 and that when studying younger age categories, maternal effect is even stronger than with our cut-off of 13 years.

We also had the possibility to take into account several potential confounding factors. In order to ensure the relevance of confounders, we focused on early-life factors and exposures that took place before the onset of asthma.

\section{Synthesis with previous knowledge}

Our finding of the importance of maternal asthma for early-onset persistent asthma is consistent with the results from the two previous 6-year longitudinal studies $[2,8]$ as well as from the two cross-sectional studies [1,9]. The Tasmanian Longitudinal Health Study provides complementary evidence of the role of maternal asthma in reducing experience of remission in adulthood [22].

London et al. reported that siblings with asthma predict different clinical types of asthma [1]. However, contrary to their results we found that also siblings strongly predicted persistent asthma and early-onset persistent asthma and not late-onset persistent asthma. We also found an elevated risk ratio between siblings with asthma and transient asthma which is partially reflected in the results of London et al. in that they found an association between siblings with asthma and wheeze and asthma-like illness without diagnoses which might be close to our subgroup of transient asthmatics [1]. 
In one previous study the risk factors of transient wheeze were studied during the first 4 years of life. Also here it was shown that parental asthma and allergic eczema and allergic rhinitis were not related to transient wheezing [23]. This study strengthens the hypothesis, that transient asthma is more related to environmental exposures, since they found e.g. that maternal active smoking in pregnancy and childhood day care center attendance generated a risk for transient wheeze.

As in the studies of London et al. and Rusconi et al. we found that hereditary allergic diseases also play a role in the development of the different phenotypes of asthma $[1,9]$. However, contrary to their results we didn't find an association between parental allergic disease and late-onset asthma. This is partly due to our cut-off point between early- and late-onset asthma.

As our study covered the age ranges up to 27 years, our choice of the cut-off point is supported by the study of Miranda et al. finding that children with asthma onset before the age of 12 years have more allergen sensitivity and allergic symptoms than those with a later onset, so this could form its own phenotype [21]. The differences in hereditary patterns related to early- and late-onset persistent asthma could be partly due to different inflammatory mechanisms, as suggested by the results of Miranda et al.

Our study suggests that both paternal and maternal asthma are related to personal asthma of the child. The results concerning paternal asthma are consistent with a recent population-based case-control study on adult-onset asthma from Finland [5], but contrary to some studies focusing only on childhood asthma, where paternal asthma showed either no significant effect on small children's asthma [3] or was not analyzed [2,8].

Additionally, our study provides evidence that the effect of paternal asthma continues longer than that of maternal asthma (Figure 1). One study conducted on children has also found an impact of paternal asthma on late-onset wheezing when looking at children 6-7 years of age and new-onset wheezing in the previous 12 months [9]. Our findings are in line with a hypothesis that gene-environment interaction is more prominently related to paternally inherited genes. A recent review proposed that maternal influence on IgE-levels of the child begins from antenatal stage and lasts through childhood, while paternal effect on IgE begins later in childhood and increases later on [24]. However, this gives no explanation to the fact that the influence of paternal allergic diseases doesn't continue to young adulthood underlining the complexity of hereditary patterns in asthma and allergic diseases.

\section{Conclusions}

The results of this population-based 20-year prospective cohort study provide evidence that different subtypes of asthma have different hereditary patterns. While family history of asthma and allergic diseases increase overall the risk of asthma through childhood and young adulthood, the strongest effect of family history of asthma and allergic diseases is seen on the subgroups of persistent- and earlyonset asthma. It seems that some subtypes are more correlated with environmental exposures and that some of the impact of the family history of asthma might also be preventable by avoiding environmental factors. Our results suggest that gene-environment interactions need further investigation. For clinicians, they strengthen the evidence that in assessing the patient's prognosis and altogether the risk of asthma subtypes, a thorough family history of asthma and allergic diseases is required.

\section{Consent}

Written informed consent was obtained from the patient for the publication of this report and any accompanying images.

\section{Abbreviations}

SHS: Second-hand smoke exposure; RR: Risk ratio; 95\% Cl: 95 percent confidence interval.

\section{Competing interests}

The authors declare that they have no competing interests.

\section{Authors' contributions}

EP conducted the analyses and drafted the first version of the manuscript. MJ participated in the planning of the study and revised the manuscript for critical content. AR contributed to the analyses and revised the manuscript for critical content. TH participated in the planning of the study and data collection and revised the manuscript. JJ participated as the PI of the study, contributed to planning, analyses and writing of the manuscript. He is the corresponding author and responsible for the integrity of the study as whole. All authors read and approved the final manuscript.

\section{Author details}

${ }^{1}$ Center for Environmental and Respiratory Health Research, University of Oulu, PO Box 5000, Fl-90014 Oulu, Finland. ${ }^{2}$ Respiratory Medicine Unit, Department of Medicine, Oulu University Hospital, Oulu, Finland. ${ }^{3}$ Respiratory Medicine Unit, Institute of Clinical Medicine, University of Oulu, Oulu, Finland. ${ }^{4}$ Public Health, Institute of Health Sciences, University of Oulu, Oulu, Finland.

${ }^{5}$ Medical Research Center Oulu, University of Oulu, Oulu, Finland.

Received: 30 September 2014 Accepted: 12 November 2014

Published online: 27 November 2014

\section{References}

1. London SJ, Gauderman JW, Avol E, Rappaport EB, Peters JM: Family history and the risk of early-onset persistent, early-onset transient, and late-onset asthma. Epidemiology 2001, 12(5):577-583.

2. Martinez FD, Wright AL, Taussig LM, Holberg CJ, Halonen M, Morgan WJ: Asthma and wheezing in the first six years of life. The group health medical associates. N Engl J Med 1995, 332(3):133-138.

3. Litonjua AA, Carey VJ, Burge HA, Weiss ST, Gold DR: Parental history and the risk for childhood asthma. Does mother confer more risk than father? Am J Respir Crit Care Med 1998, 158(1):176-181.

4. Paaso EMS, Jaakkola MS, Lajunen TK, Hugg TT, Jaakkola JJK: The Importance of Family History in Asthma during the First 27 Years of Life. Am J Respir Crit Care Med 2013, 188:624-626.

5. Lajunen TK, Jaakkola JJ, Jaakkola MS: Influence of heredity on asthma continues to adulthood. J Allergy Clin Immunol 2013, 131(3):916-918.

6. Ballardini N, Kull I, Lind T, Hallner E, Almqvist C, Ostblom E, Melen E, Pershagen G, Lilja G, Bergstrom A, Wickman M: Development and 
comorbidity of eczema, asthma and rhinitis to age 12: data from the BAMSE birth cohort. Allergy 2012, 67(4):537-544.

7. Savenije OE, Granell R, Caudri D, Koppelman GH, Smit HA, Wijga A, de Jongste JC, Brunekreef B, Sterne JA, Postma DS, Henderson J, Kerkhof M: Comparison of childhood wheezing phenotypes in 2 birth cohorts: ALSPAC and PIAMA. J Allergy Clin Immunol 2011, 127(6):1505-1512. e14.

8. Granell R, Sterne JA, Henderson J: Associations of different phenotypes of wheezing illness in early childhood with environmental variables implicated in the aetiology of asthma. PLoS One 2012, 7(10):e48359.

9. Rusconi F, Galassi C, Corbo GM, Forastiere F, Biggeri A, Ciccone G, Renzoni E: Risk factors for early, persistent, and late-onset wheezing in young children. SIDRIA Collaborative Group. Am J Respir Crit Care Med 1999, 160(5 Pt 1):1617-1622.

10. Jaakkola JK, Jaakkola N, Ruotsalainen R: Home dampness and molds as determinants of respiratory symptoms and asthma in pre-school children. J Expo Anal Environ Epidemiol 1993, 3(Suppl 1):129-142.

11. Jaakkola JK, Hwang BF, Jaakkola MS: Home dampness and molds as determinants of allergic rhinitis in childhood: a 6-year, population-based cohort study. Am J Epidemiol 2010, 172(4):451-459.

12. Venn A, Lewis S, Cooper M, Hill J, Britton J: Questionnaire study of effect of sex and age on the prevalence of wheeze and asthma in adolescence. BMJ 1998, 316(7149):1945-1946.

13. Melen E, Kere J, Pershagen G, Svartengren M, Wickman M: Influence of male sex and parental allergic disease on childhood wheezing: role of interactions. Clin Exp Allergy 2004, 34(6):839-844.

14. Almqvist C, Pershagen G, Wickman M: Low socioeconomic status as a risk factor for asthma, rhinitis and sensitization at 4 years in a birth cohort. Clin Exp Allergy 2005, 35(5):612-618.

15. Fredriksson P, Jaakkola N, Jaakkola JK: Breastfeeding and childhood asthma: a six-year population-based cohort study. BMC Pediatr 2007, 7:39.

16. Burke H, Leonardi-Bee J, Hashim A, Pine-Abata H, Chen Y, Cook DG, Britton JR, McKeever TM: Prenatal and passive smoke exposure and incidence of asthma and wheeze: systematic review and meta-analysis. Pediatrics 2012, 129(4):735-744.

17. DerSimonian R, Laird N: Meta-analysis in clinical trials. Control Clin Trials 1986, 7(3):177-188.

18. Hertzmark E, Spiegelman D: [http://www.hsph.harvard.edu/donnaspiegelman/software/metaanal/]

19. Daly L: Simple SAS macros for the calculation of exact binomial and Poisson confidence limits. Comput Biol Med 1992, 22(5):351-361.

20. Pattaro C, Locatelli F, Sunyer J, de Marco R: Using the age at onset may increase the reliability of longitudinal asthma assessment. J Clin Epidemiol 2007, 60(7):704-711.

21. Miranda C, Busacker A, Balzar S, Trudeau J, Wenzel SE: Distinguishing severe asthma phenotypes: role of age at onset and eosinophilic inflammation. J Allergy Clin Immunol 2004, 113(1):101-108.

22. Burgess JA, Matheson MC, Gurrin LC, Byrnes $G B$, Adams $K S$, Wharton $C L$, Giles GG, Jenkins MA, Hopper JL, Abramson MJ, Walters EH, Dharmage SC: Factors influencing asthma remission: a longitudinal study from childhood to middle age. Thorax 2011, 66(6):508-513.

23. Rancière F, Nikasinovic L, Bousquet J, Momas I: Onset and persistence of respiratory/allergic symptoms in preschoolers: new insights from the PARIS birth cohort. Allergy 2013, 68:1158-1167.

24. Wu CC, Chen RF, Kuo HC: Different implications of paternal and maternal atopy for perinatal IgE production and asthma development. Clin Dev Immunol 2012, 2012:132142.

\section{Submit your next manuscript to BioMed Central and take full advantage of:}

- Convenient online submission

- Thorough peer review

- No space constraints or color figure charges

- Immediate publication on acceptance

- Inclusion in PubMed, CAS, Scopus and Google Scholar

- Research which is freely available for redistribution 